Pak. j. sci. ind. res. Ser. A: phys. sci. 2021 64A(1) 65-75

\title{
Design Optimization and Analysis of Rotor Blade for Horizontal-Axis Wind Turbine Using Q-Blade Software
}

\author{
Muhammad Mujahid, Abdur Rafai, Muhammad Imran*, \\ Mustansar Hayat Saggu and Noor Rahman \\ Department of Mechanical Engineering, FET, IIU, Islamabad, Pakistan
}

(received August 19, 2019; revised February 7, 2020; accepted February 11, 2020)

\begin{abstract}
Wind energy plays a tremendous role in energy power sector in terms of wind turbine. Engineers and scientists are trying to improve the wind turbine design in order to get the maximum power efficiency from the wind, which is one of the most cheap and common renewable resource in nature. The objective of this study was to design a horizontal wind turbine rotor blade for a site of known wind data in order to extract the maximum power efficiency from the wind by using blade element theory analysis and Q-Blade simulation. Eight different aerofoils of different thicknesses from two NACA family 55xx and 00xx were considered for this study. The four different rotor blades were designed having length of 25 meter. Each blade consists of the combination of these NACA aerofoils which are oriented at different angles of attack and to simulate it at different Reynolds numbers. Comparative study was done to find the optimum blade design by considering the power output at two different rotational speeds and observe the effects of changing chord length and twist angle of final selected blade on these power output.
\end{abstract}

Keywords: wind energy, Q-Blade simulation, BEM theory, HAWT rotor blade, reynolds number

\section{Introduction}

The extraction of power energy from wind is becoming more popular (Kaveh and Sabeti, 2019) day by day because of two main reasons (Chaudhary and Prakash, 2019; Kaveh and Sabeti, 2019; Raut et al., 2017). The first reason is environmental friendly and the second one is its availability for free almost throughout the year (Hassanli et al., 2018; Saeed, 2018). This is the main reason that this area becomes more interest for the researcher, scientist and engineers to maximize the power efficiency from the wind resources by altering the size and shape of the wind turbine most commonly the rotor blade (Drumheller et al., 2015). Design and analysis for any application is critical to the service life and economics of the structures (Imran et al., 2019a, $\mathrm{b}$ and $\mathrm{c} ; 2018)$.

Turbine is basically divide into two most common types, horizontal axis wind turbine (HAWT) and vertical axis wind turbine (VAWT) (Das and Talapatra, 2016). These are distinguished by the rotor design and rotating axis, each with its own favourable features (Hau, 2006). However, VAWT designs are not capable of producing a power in megawatt scale and need more development, so that it can be considered to compete with HAWT, while the popularity of HAWT can be attributed to

*Author for correspondence;

E-mail: Muhammad.imran@iiu.edu.pk increased rotor control through pitch and yaw control (Schubel and Crossley, 2012).

If we consider the power output of wind turbine, it can be divided into different categories as small (power output less than $100 \mathrm{~kW}$ ) and medium (power output between 100kW-1MW) (Tong, 2010). Small and medium wind turbines are essentially used for small home or villages to generate electricity (Lanzafame and Messina, 2010).

Since optimal rotor blade and high power efficiency is required for maximum power extraction from wind energy but the maximum energy that can be extracted from wind is $59 \%$, which is explained by Bitz law (Broberg et al., 2018) and it is widely accepted (Gorban et al., 2001). Since in real practice the rotor design experiences some of minor losses like tip losses, wake effects and drive train efficiency losses; so, the maximum theoretical power efficiency has not yet been to achieved (Yurdusev et al., 2006).

HAWT are very sensitive to changes in blade profile and design (Tang et al., 2019). The most common parameters that influence the HAWT performance are, aerofoils selection, Reynolds number, tip speed ratio, chord length and twist angle (Ceyhan, 2012).

Successful blade design must satisfy a wide range of objectives too, some of which can be in conflict. These 
objectives are to (1) Maximize annual energy production, (2) Restrict the maximum power output in the turbine, (3) Endure fatigue loads, (4) Limit tip deflections to avoid blade and tower collisions, (5) Prevent resonances, (6) Minimize weight and cost. The design process can be divided into two stages that the aerodynamic design, in which objectives (1) and (2) are satisfied, and the structural design. The aero dynamic design addresses the selection of the optimum geometry of the blade and the external surface, also referred to as the blade geometry. The blade geometry is defined by the aerofoil family and the chord, twist and thickness distribution. The structural design consists of blade material selection and determination of a structural cross section or spar within the external envelope that meets objectives (4) to (6) (Bossanyi et al., 2012).

For easiness during the production, several simplifications should be maintained along the process such as reducing the angle of twist, linearization of the chord width and reducing the number of different aerofoil profiles.

The aim of this study is to determine the aero dynamic performance of eight different aerofoils viz. 0020, 0018, $0015,0012,5520,5518,5515$, and 5512 at different Reynolds number for rotor with 3 blades and $25 \mathrm{~m}$ radius using Q-Blade software and to find the optimum blade design for a specific wind corridor.

\section{Material and Methods}

Simulation and modeling. The main focus of this research is the rotor blade design because the horizontal wind turbines are highly sensitive to changes in blade profile and design, allowing great improvements when it comes to efficiency. The all simulation is carried in by Q-Blade software version 0.96 . The software QBlade is to developed as an open source framework for the simulation and design of wind turbines.

In this study eight different NACA aerofoils from 4digit family (i.e. 0020, 0018, 0015, 0012, 5520, 5518, 5515 and 5512) were selected. The NACA 4-digit aerofoil family has some advantages over the rest of the aerofoil family. The 4-digit has acceptable stall characteristics, a small centre of pressure movement across large speed range and they are less sensitive to roughness. Besides this, the type of aerofoils has a slightly low maximum lift coefficient, a high drag coefficient and a high pitching moment. Nonetheless, they have been used in several applications in general aviation, horizontal tails and HAWT with excellent performance. These aerofoils were simulated at different Reynolds number which was calculated according to minimum and maximum wind speed at given site by means of following expression:

$$
\mathrm{Re}=\mathrm{Vc} / \mathrm{v}
$$

where:

$v=$ velocity of wind; $\mathrm{c}=$ chord width and $v=$ kinametic viscocity of air. Four different Reynolds number were determined, two for each according to minimum wind speed i.e. $5 \mathrm{~m} / \mathrm{sec}$ and maximum wind speed i.e. 14 $\mathrm{m} / \mathrm{sec}$ from a wind data of Jamshoro, with respect to maximum and minimum chord length, and then choose average value of Reynolds number from these four wind speed data that is 400000 and 1200000 . However, the operating wind turbine blade elements experience different Reynolds numbers due to variable wind speed, chord width and different blade span locations. After Reynolds number calculation, the coefficient of lift and drag with respect to angle of attack i.e. -5 to 25 were calculated by simulating all these NACA aerofoils at each Reynolds number by using Q-Blade software. After aerofoils simulation, beam element theory (BEM) formulation was implemented to find the optimal blade rotor design. The length of rotor blade of 25 meter was considered in this study. The parameters such as chord length and twist angle for optimum blade design were derived from the following formulas (Wang et al., 2012).

$\mathrm{C}_{\mathrm{l}, \mathrm{n}}=\left(\mathrm{C}_{\mathrm{i}, \theta}-0.3\right)+0.3 \frac{(\mathrm{n}-1)}{\mathrm{N}} \mathrm{n}=1,2, \ldots . \mathrm{N}+1 \ldots$.

$\theta_{1, n}=\left(\theta_{i, \theta}-6\right)+12 \frac{(n-1)}{N} n=1,2, \ldots . . N+1$

where:

$\mathrm{n}=$ indicates the $\mathrm{nth}$ case; $\mathrm{C}_{\text {in }}$ and $\theta_{\text {in }}$ are the chord and twist angle at the ith blade element of the nth case respectively.

And by using other equation (Hau, 2006)

$\mathrm{C}_{\mathrm{opt}}=\frac{2 \pi \mathrm{r}}{\mathrm{n}} \frac{8}{9 \mathrm{C}_{\mathrm{L}}} \frac{\mathrm{U}_{\mathrm{wd}}}{\lambda \mathrm{V}_{\mathrm{r}}}$ where $\mathrm{V}_{\mathrm{r}}=\sqrt{\mathrm{V}_{\mathrm{w}}^{2}+\mathrm{U}^{2}} \ldots$

where:

$\mathrm{r}=$ radius $(\mathrm{m}) ; \mathrm{n}=$ Blade numbers; $\mathrm{C}_{\mathrm{L}}=$ coefficient of lift; $\lambda=$ local tip speed ratio; $V_{\mathrm{r}}=$ Local resultant air velocity; $\mathrm{U}=$ wind speed; $\mathrm{U}_{\mathrm{wd}}=$ design wind speed; $\mathrm{C}_{\mathrm{opt}}$ 
$=$ Optimum chord length .

And the twist angle from equation (Manwell et al., 2010).

$$
\begin{aligned}
& \Phi_{\mathrm{i}}=\left(\frac{2}{3}\right) \tan ^{-1} \frac{1}{\lambda_{\text {r.i }}} \\
& \theta_{\mathrm{p}, \mathrm{i}}=\Phi_{\mathrm{i}}-\alpha
\end{aligned}
$$

where:

$\mathrm{i}=$ ith blade element; $\lambda_{\mathrm{T}, \mathrm{i}}=$ local tip speed ratio; $\Phi_{\mathrm{i}}=$ relative angle of wind at $i_{\text {th }}$ blade element, and $\theta_{\mathrm{p}, \mathrm{i}}=$ twist angle of $i_{\text {th }}$ blade element.

After calculation of these parameters, data was implemented into Q-Blade software to design rotor blade for further simulation. The NACA aerofoils that are selected were used in combination by 4 different ways at different sections in the designed rotor blade so, that we have 4 different blades (i.e. 55xx multi blade, 00xx multi blade, 00xx55xx multi blade and 55xx00xx multi blade) of same length, same twist angle and same chord length but different aerofoils as shown in Fig. 1-3. Because the use of the same single aerofoil for the entire blade length would result in an inefficient design (Maalawi and Badr, 2003). By finding the coefficient of power (Cp) verses tip speed ratio (TSR) and Power (Hassanli et al., 2018) verses wind speed at two Reynolds number i.e. 400,000 and 1,200,000 at two different rotational speeds, the optimum rotor blade on base of maximum power output was selected.

After selection of optimum blade, the chord length and twist angle were changed to find the effects of both these parameters on power output of rotor. The losses factors such as tip losses, root losses and Reynolds drag corrections also considered throughout the simulations.

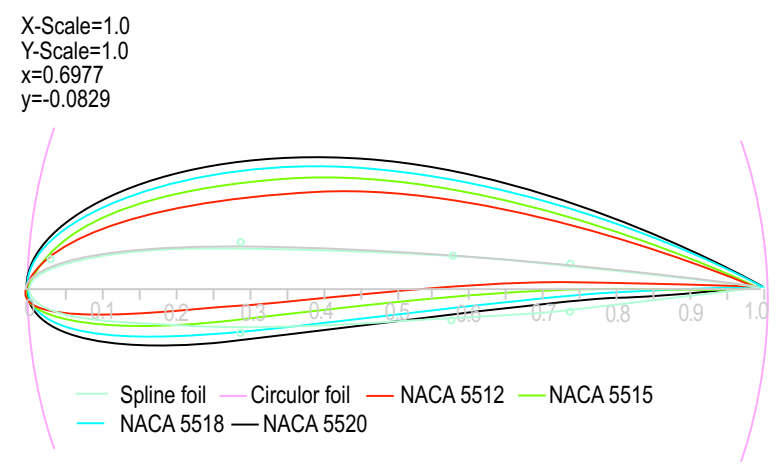

Fig. 1. NACA family 55xx aerofoils profile.

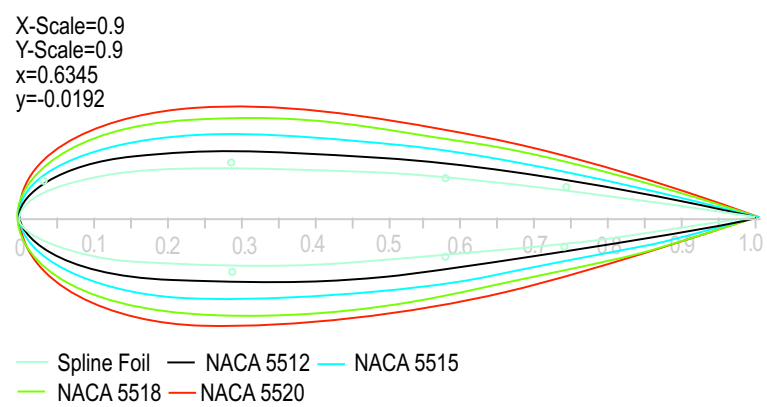

Fig. 2. NACA family 00xx aerofoils profile.

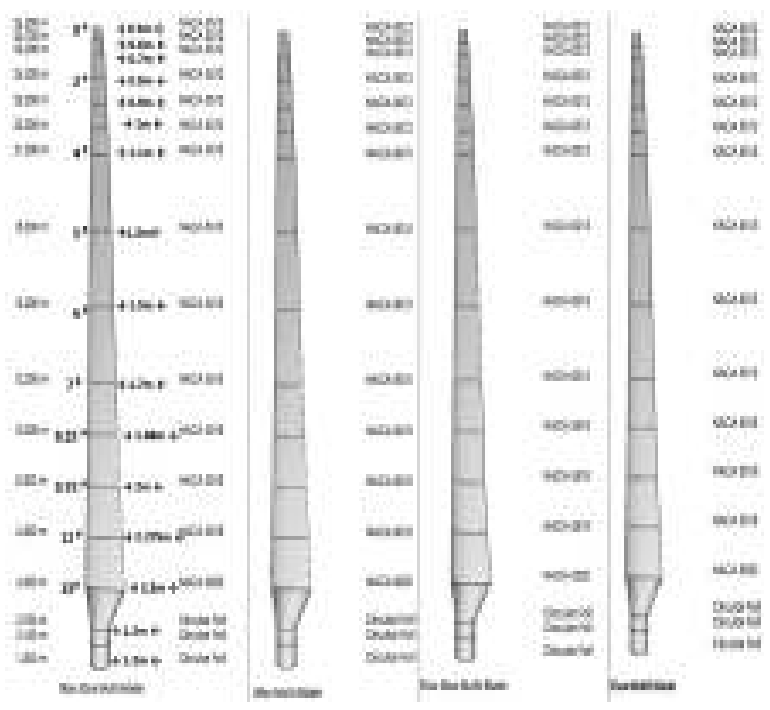

Fig. 3. Four different Rotor blade profiles design from Q-blade.

In the end, the optimal blade design selected on base of maximum power output efficiency, and it was evaluated for the distributions of aerodynamic loads at each blade section at wind speed of $15 \mathrm{~m} / \mathrm{s}$ because the maximum speed at selected site is $14 \mathrm{~m} / \mathrm{s}$. The aero dynamic loads were calculated by blade element momentum theory formulation as given below:

$$
\begin{aligned}
& d F x=C x . d q \\
& d F y=C y . d q
\end{aligned}
$$

where:

$$
\begin{aligned}
& \mathrm{Cx}=\mathrm{C}_{\mathrm{L}} \sin \Phi-\mathrm{C}_{\mathrm{d}} \cos \Phi \\
& \mathrm{Cy}=\mathrm{C}_{\mathrm{L}} \cos \Phi+\mathrm{C}_{\mathrm{d}} \sin \Phi \\
& \tan \Phi=\frac{(1-\mathrm{a}) \mathrm{V}_{\mathrm{o}}}{(1-\mathrm{a} ") \Omega_{\mathrm{r}}} \ldots \ldots \ldots . . .
\end{aligned}
$$




$$
\mathrm{dq}=1 / 2 \rho \mathrm{w}^{2} \mathrm{cdr} .
$$

The differential thrust and torque can be find by:

$$
\begin{aligned}
& \mathrm{dT}=\text { BCydq } . \\
& \mathrm{dQ}=\text { BCxdqr }
\end{aligned}
$$

where:

$\mathrm{c}=$ chord length $\Omega=$ rotational speed of rotor.

The range of winds used for the analysis was between the maximum (i.e. $14 \mathrm{~m} / \mathrm{s}$ ) and minimum (i.e. $5 \mathrm{~m} / \mathrm{s}$ ) wind speed at the height of $50 \mathrm{~m}$, encountered in Jamshoro during the wind site evaluation conducted by Pakistan Meteorological Department as shown in Fig. 4.

Beam element theory is implemented for the design of optimal rotor blade as shown in Fig. 3. Eight different aerofoils from two NACA 4-digits family were selected according to thickness and Reynolds number performance by using wind speed data at online airfoil tools. com and simulate all these eight aerofoils at Q-blade software were simulated.

\section{Results and Discussion}

The analysis of the designed rotor blade by using Qblade software. First, the different NACA aerofoils and their aerodynamics parameter such as coefficient of lift and drag vs angle of attack will be discussed, than rotor blades performance such as coefficient of power $v s$ TSR, and power output with respect to wind speed and in the last the thrust force and moment force at each section of optimal rotor blade.

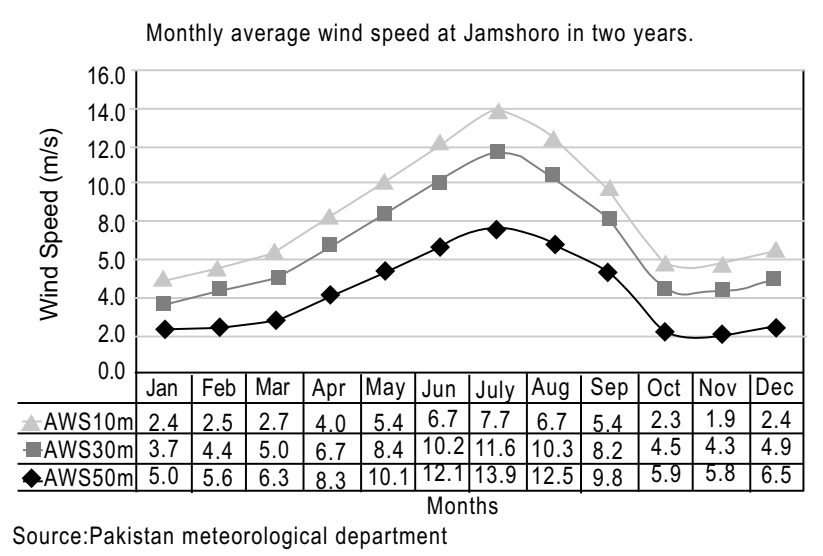

Fig. 4. Wind speed data of Jamshoro by Pakistan meteorological department.
Aerodynamics of aerofoils. The analysis is done by Q-Blade by using eight different aerofoils from 2 NACA 4-digit families that is $0020,0018,0015,0012$, and $5520,5518,5515,5512$. The last two digits of each aerofoil represent the max thickness as shown in Fig. 2-3. The results from Q-Blade software simulation for each aerofoils at different Reynolds numbers (i.e. 400000 , 800000 and 1200000) in between CL/Cd vs angle of attack are presented in Fig. 5.

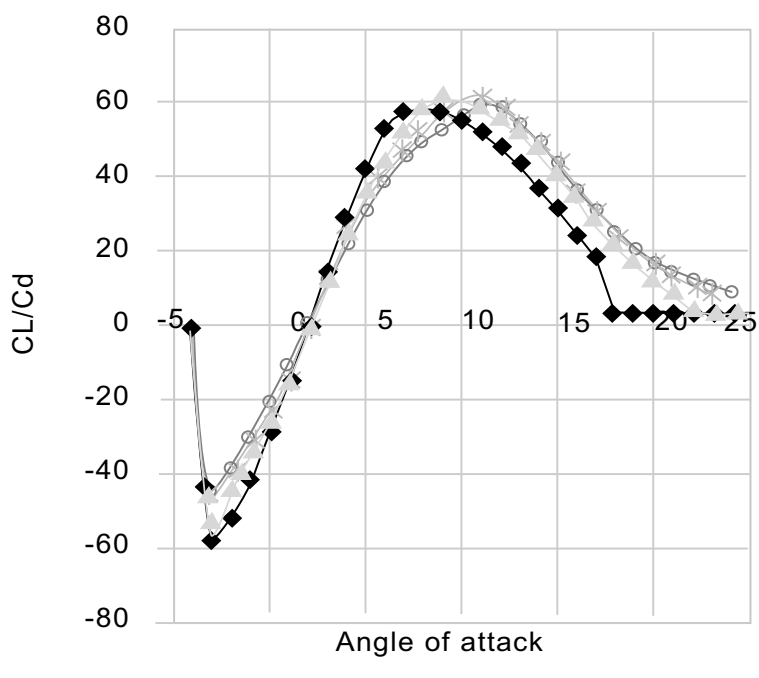

$\operatorname{Re}-400,000$

- NACA 5512 NACA5515

* NACA 5518 -NACA 5520

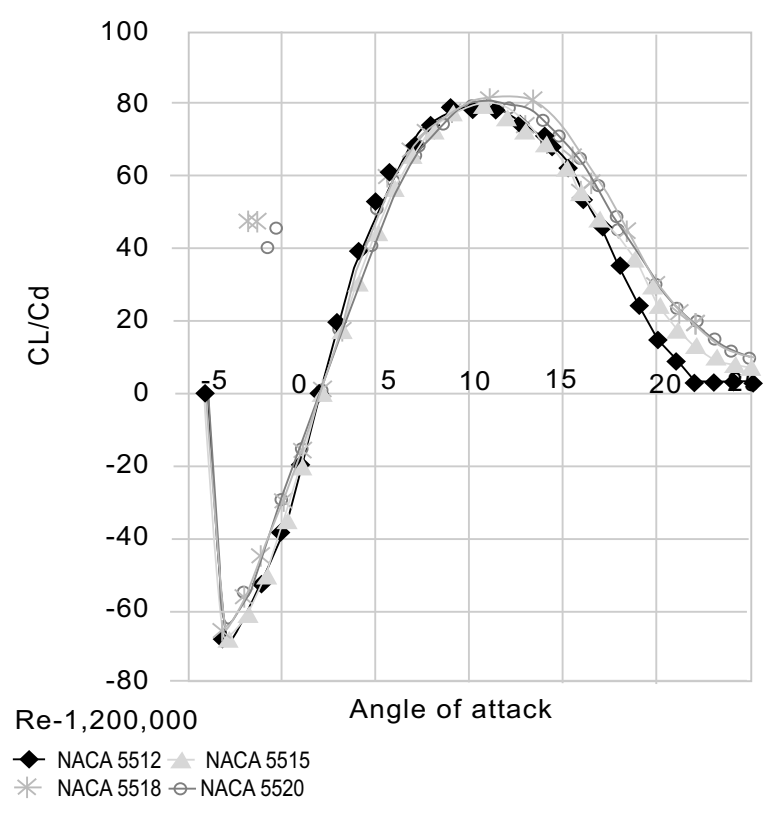

Fig. 5. Graphs between $\mathrm{Cl} / \mathrm{Cd}$ vs angle of attack of NACA aerofoils 00xx family at different Reynolds number from Q-blade simulation. 
In this section the selected two NACA families are considered for comparison. The comparison is done at different angles of attack from -5 to 25 degree for maximum $\mathrm{Cl} / \mathrm{Cd}$ ratio. It can be seen from Fig. 5-6, that the coefficient of lift-to-drag ratio for NACA family $00 \mathrm{xx}$ is almost same at all thicknesses. The maximum $\mathrm{Cl} / \mathrm{Cd}$ value is achieved at an angle of approximately $8-12$ degrees, while it's maximum value

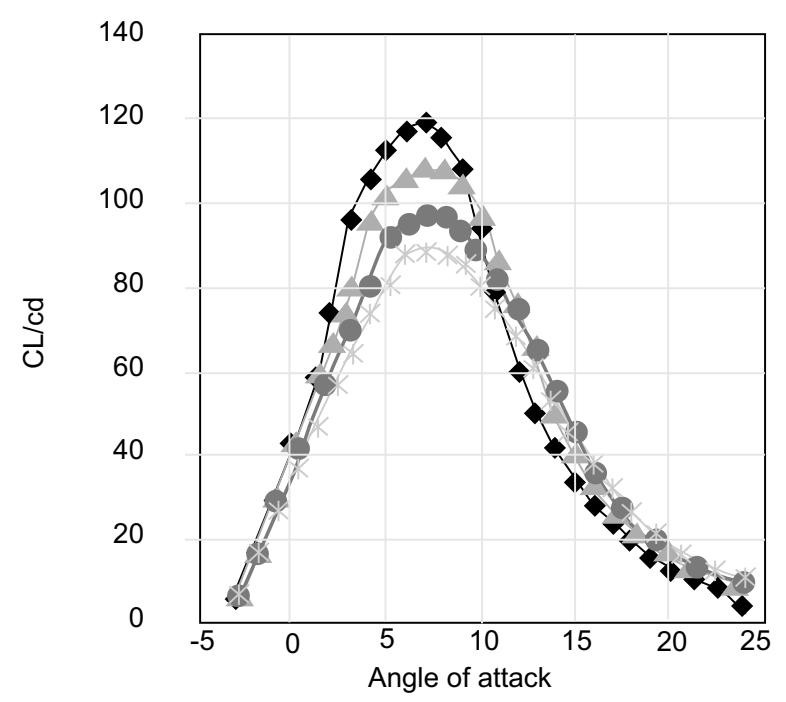

Re-a400,000

— NACA 5512 - NACA5515 - NACA 5518

NACA 5520

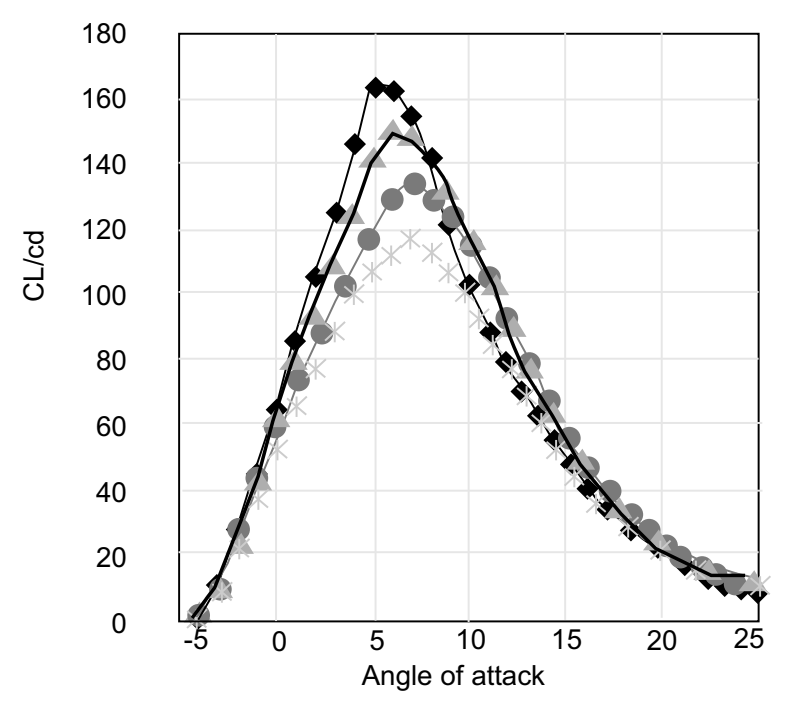

$\operatorname{Re}-1,200,000$

- NACA $5512 \rightarrow$ NACA5515 - NACA 5518

NACA 5520

Fig. 6. Graphs between CL/CD vs angle of attack of NACA aerofoils $55 \mathrm{xx}$ family at different Reynolds number from Q-blade simulation. is different at different Reynolds number. At Re-400000 the maximum coefficient of lift-to-drag ratio is almost 60 and at Re-1200000 it is increased and the maximum value reaches to 80 .

On the other hand, the coefficient of lift-to-drag ratio for NACA family $55 \mathrm{xx}$ is gradually increased as the thickness of the aerofoils decreases. For this NACA family the maximum $\mathrm{Cl} / \mathrm{Cd}$ is approximately achieved at an angle of 5-7 degree. The maximum $\mathrm{Cl} / \mathrm{Cd}$ is observed by NACA 5512 at both different Reynolds number that is 120 for Re-400000 and almost 165 at Re-1200000. It is also clearly seen that the NACA foils family 00xx have negative coefficient of lift-to-drag ratio below 3 degree of angle of attack as shown in Fig. 5. The difference between $\mathrm{Cl} / \mathrm{Cd}$ of these two NACA families is due to the shape of foils as shown in Fig. 2-3.

By observing these results, the max coefficient of liftto-drag ratio occurred at different angles of attack of each aerofoil. Thus the aerofoils can be choosen for different applications that are depending upon the aerodynamic parameters requirement. While for particular applications not only $\mathrm{Cl} / \mathrm{Cd}$ ratio is considered but other parameters such as maximum camber and maximum thickness are also considered.

The reason of low coefficient of lift-to-drag ratio at low Reynolds number is that, NACA profiles are usually developed for high Reynolds number and thus suffer from significant laminar separation bubbles when it operate at low Reynolds number. Due to this laminar separation the coefficient of lift decreases, while coefficient of drag increases gradually (Alom and Saha, 2019).

Power efficiency. Coefficient of power versus tip speed ratio. After the complete simulation and evaluation of all aerofoils by means of coefficient to lift, coefficient of drag and angle of attack, these aerofoils were further used in the design blade at different sections by considering root, span, tip and twist angle is four different ways and its performance evaluated with respect to power coefficient, Tip speed ratio and power output. Mean value of wind speed was calculated as $9 \mathrm{~m} / \mathrm{s}$ from a selected site. Fig. 7 show the graphs between coefficient of power vs tip speed ratio at two different Reynolds number and was obtained from Q-Blade.

It is seen from graphs that for all different rotor blades, the coefficient of power value initially increases, reaches 

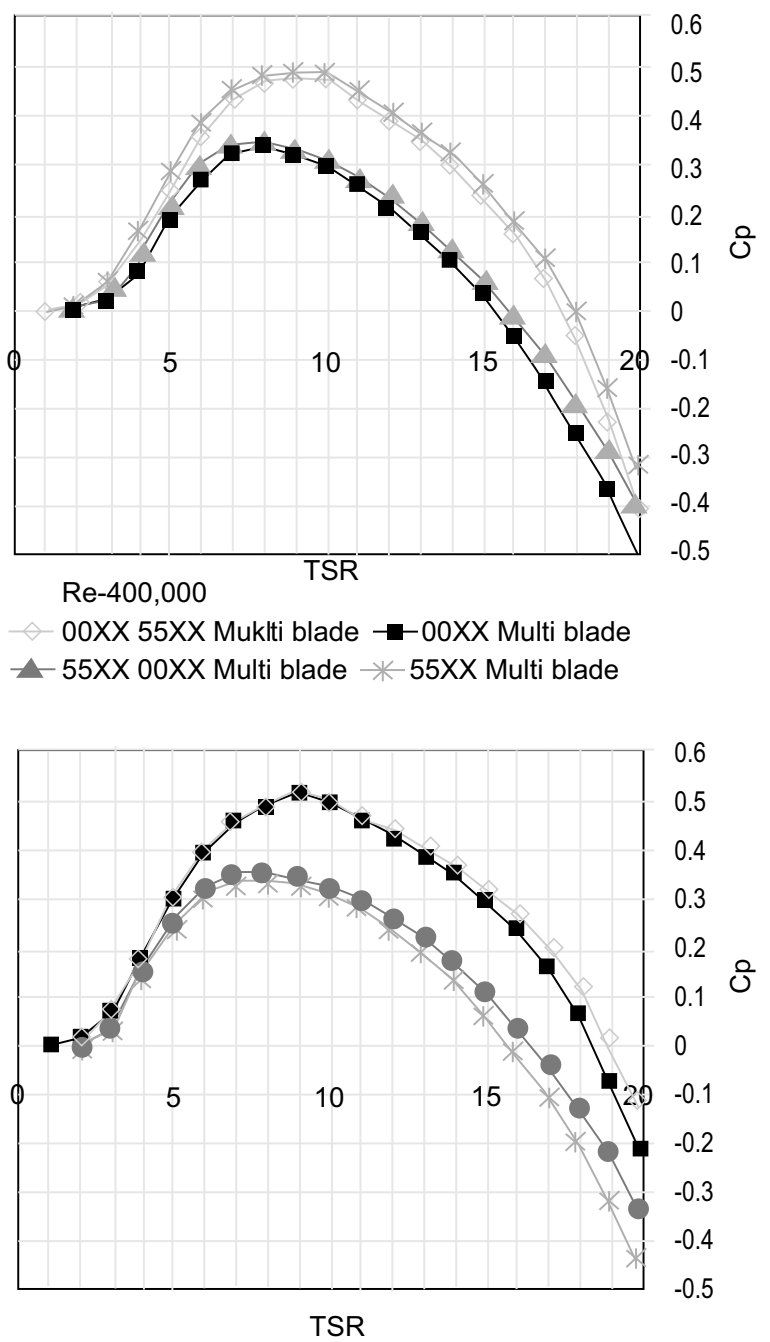

Re-1,200,000

- 00XX 55XX Muklti blade $\rightarrow$ 00XX Multi blade

- 55XX 00XX Multi blade $\diamond 55 X X$ Multi blade

Fig. 7. Graph between coefficient of power and tip speed ratio at two different Reynolds number from Q-blade simulation.

to maximum and then decrease gradually with increase in tip speed ratio.

Also it was observed that maximum $\mathrm{Cp}$ value occurs at different values of TSR for different blades i.e. at Re-400000, for Blade 00xx and 55xx00xx, Cp maximum (i.e. 0.35 ) is obtained at $\mathrm{TSR}=8$, whereas for blades $55 \mathrm{xx}$ and $00 \mathrm{xx} 55 \mathrm{xx}, \mathrm{C}_{\mathrm{pmax}}$ obtained at $\mathrm{TSR}=10$, that is approximately 0.48 . Similarly at Re- 1200000 , the $\mathrm{C}_{\mathrm{pmax}}$ for blades $00 \mathrm{xx}$ and $55 \mathrm{xx} 00 \mathrm{xx}$ is almost same as that is at Re-40, but the TSR decrease to 7. The same situation also observed for blades $55 \mathrm{xx}$ and $00 \mathrm{xx} 55 \mathrm{xx}$ which gives maximum power coefficient (i.e. approx. 0.5 to 0.52 ) now at $\mathrm{TSR}=9$.

It is clear in graphs that simulation and the Reynolds number increases and shows the maximum power coefficient was obtained at more low tip speed ratio. Tip speed ratio is basically the ratio between the wind speed and the rate of rotor rotation. Generally a high TSR is a desirable feature for horizontal wind turbine, since it results in a high shaft rotation and a result at high power extraction but on the other side, if blade rotor turns too fast, the rotating blades act like a solid wall for incoming wind flow, resulting in reduced power extraction. The rotating of rotor too slowly is also not desirable because most of the wind will pass without interaction with rotor blades and hence little power extracted (Song et al., 2018).

Power output verses wind speed. The main objective of this research was to select an optimal design for the specific wind corridor. So, in this section we will briefly describes the power output of all four designed blades with respect to wind speed and find the best one which gives the maximum power output at desirable wind speed for the given site. For this purpose the four different blade designs were simulated at Q-blade at two different rotational speeds of rotor blades (i.e. rpm 20 and 25) and two different Reynolds number that was calculated early according to minimum and maximum wind speeds. The power output of our concern was 5 $\mathrm{m} / \mathrm{s}$ to $14 \mathrm{~m} / \mathrm{s}$ that is a minimum and maximum wind speed of selected area but simulation was taken from $0-30 \mathrm{~m} / \mathrm{s}$.

It is seen from Fig. 8-9 and Table 1-2, the cut in speed for each blade is $5 \mathrm{~m} / \mathrm{s}$, but whenever the speed of wind increases, the difference in power output is observed for each blade profiles with respect to Reynolds number and rotational speed of rotor blade. If we compare the power verses wind speed with respect to Reynolds number, it is clearly observed that at low Reynolds number (i.e. $\mathrm{R}=40 \mathrm{E} 4$ ), the power output at each wind speed is lower than that of observed for high Reynolds number (i.e. Re-120E4). Also it was observed that the blade profiles $55 \mathrm{xx}$ and $00 \mathrm{xx} 55 \mathrm{xx}$ give maximum power output at each wind speed and each Reynolds number, while the other two blades $00 \mathrm{xx}$ and $55 \mathrm{xx} 00 \mathrm{xx}$ give minimum power output.

However, the rotational speed is also greatly influenced on the power efficiency of these rotors blades as shown in Fig. 7-8 and Table 1-2. It is clearly observed that at 


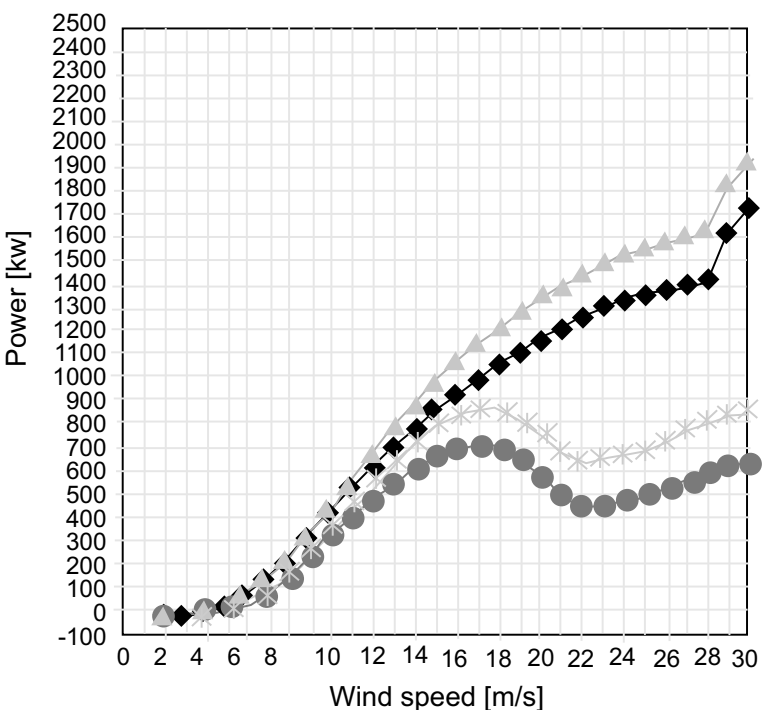

- 00XX 55XX Blade $\neg$ 00XX 55XX Blade $-55 X X$ Blade $* 55 X X 00 X X$ Blade
Re-400,000 rpm-20

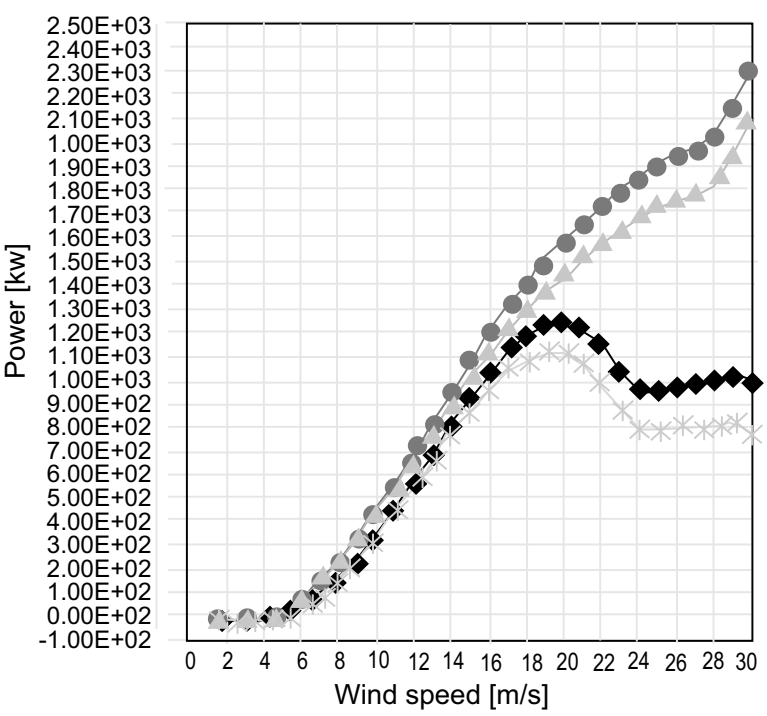

00XX Blade $\prec$ 55XX 00XX Blade 00XX 55XX Blade $*$ 00XX Blade
$\operatorname{Re}-1,200,000$ rpm-20

Fig. 8. Graph between power vs wind speed at $20 \mathrm{rpm}$ from Q-blade.

rotational speed of $20 \mathrm{rpm}$, the power output is small as compared to high rotation speed. At high rotational speed i.e. $25 \mathrm{rpm}$ the power output is gradually increased for all different blades profiles. The other important factor observed is that, at low rotational speed the cutin speed of HAWT blades were starting at $4 \mathrm{~m} / \mathrm{s}$ of

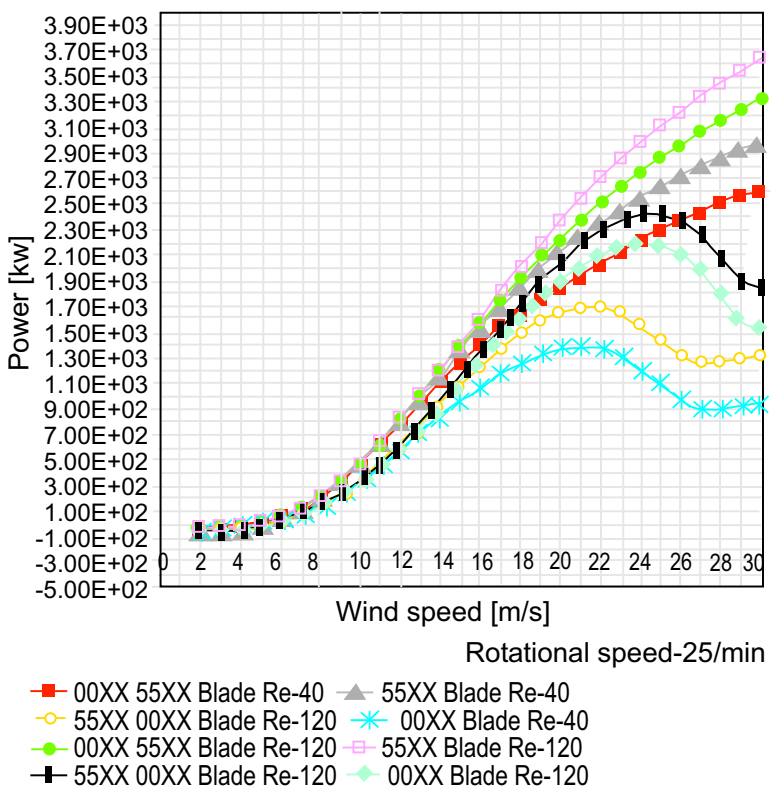

Fig. 9. Graph between power vs wind speed at Reynolds number 40E4 and 120E4 and rotational speed $25 / \mathrm{min}$. wind speed, while for rotational speed of $25 \mathrm{rpm}$, its cut $=$ in speed started at $5 \mathrm{~m} / \mathrm{s}$.

Apart from the main objective to find the optimum blade design, another important factor is also observed that, for large rotor blade, the aerofoils selection at each section throughout the blade length largely affect the power output efficiency. A close look to the graphs and table values show that, the blade profile $00 \mathrm{xx}$ consist of only 00xx aerofoils family throughout the length as shown in Fig. 3. The power output of this blade was low as compared to NACA 55XX family blade, but when we combine the NACA $55 \mathrm{xx}$ aerofoils from mid span up to tip of blade (i.e. 00xx 55xx blade) the power output gradually increased and reached somewhat near to 55xx blade profile which has high power efficiency. Similarly when the $00 \mathrm{xx}$ NACA aerofoils is combined with $55 x x$ family from mid spin up to tip, the power output efficiency observed was much low as compared to $55 \mathrm{xx}$ blade profiles.

So, from this observation, we can conclude that aerofoils that have max camber line and tailing edges can give a maximum power output, if we use it in blade profiles from mid span to tip while the aerofoils at root have not much effect on power output efficiency.

Effect of chord length and twist angle on power output. The rotor blade considered for this study is $55 \mathrm{xx}$ blade, which has high power efficiency from other three blade 
designs. The actual chord length of selected blades rotor was $2.5 \mathrm{~m}$. So, we changed the chord length throughout the blade length, while the twist angle was kept the same as the previous deigned 55xx blade. The new max chord lengths was consider 3 meter and 2 meter at the same position as that of previous blade and then it was changed throughout blade length according to formulas that have already been described in section 2 as shown in Fig. 10.
Figure 10 shows that the selected chord length has not much effect on power output efficiency with respect to wind speed. The output power is approximately same for all four blade designs up to wind speed of $14 \mathrm{~m} / \mathrm{s}$, while at high wind speed, the maximum chord blade lengths have a significant increase in power output efficiency as compared to other two.

Figure 11 is plotted between power output and wind speed at different twist angle. The optimal blade design

Table 1. Power vs wind speed at Reynold number $=400,000$

\begin{tabular}{|c|c|c|c|c|c|c|c|c|}
\hline \multirow{3}{*}{$\begin{array}{l}\text { Wind } \\
\text { speed } \\
\mathrm{m} / \mathrm{s}\end{array}$} & \multicolumn{8}{|c|}{ Power (Hassanli, et al.) } \\
\hline & \multicolumn{2}{|c|}{ 00xx 55xx Multi blade } & \multicolumn{2}{|c|}{ 00xx Multi blade } & \multicolumn{2}{|c|}{ 55xx 00xx Multi blade } & \multicolumn{2}{|c|}{ 55XX Multi blade } \\
\hline & rpm-20 & $\mathrm{rpm}-25$ & $\mathrm{rpm}=20$ & rpm-25 & rpm-20 & rpm-25 & rpm-20 & rpm-25 \\
\hline 1 & -25.3948 & -49.7708 & -21.4752 & -42.664 & -21.5026 & -42.8791 & -25.3614 & -49.8780 \\
\hline 2 & -24.7222 & -48.0237 & -24.0279 & -40.3077 & -20.5764 & -39.0077 & -21.8895 & -46.7087 \\
\hline 3 & -9.56349 & -40.1650 & -14.4824 & -41.0640 & -11.3115 & -34.3708 & -7.21338 & -34.8772 \\
\hline 4 & 21.1599 & -6.44814 & 4.30017 & -22.7345 & 7.27984 & -16.7596 & 23.2237 & -2.00342 \\
\hline 5 & 65.1603 & 41.3278 & 35.9195 & 8.39878 & 39.4725 & 14.2184 & 67.5841 & 45.3588 \\
\hline 6 & 133.764 & 106.973 & 83.2012 & 55.5994 & 88.0399 & 62.2151 & 137.673 & 111.437 \\
\hline 7 & 215.848 & 200.123 & 148.356 & 121.708 & 154.121 & 130.307 & 220.979 & 206.512 \\
\hline 8 & 315.243 & 322.608 & 230.606 & 209.015 & 238.854 & 218.779 & 323.039 & 330.635 \\
\hline 9 & 418.211 & 458.211 & 314.784 & 319.700 & 335.384 & 331.548 & 438.364 & 468.918 \\
\hline 10 & 525.254 & 615.710 & 400.570 & 450.402 & 435.267 & 466.512 & 559.654 & 630.935 \\
\hline 11 & 627.850 & 786.099 & 481.705 & 592.149 & 533.566 & 616.277 & 679.606 & 809.547 \\
\hline 12 & 704.582 & 950.169 & 541.959 & 723.354 & 629.040 & 772.369 & 791.312 & 998.076 \\
\hline 13 & 778.800 & 1114.23 & 602.996 & 853.698 & 717.942 & 928.419 & 892.186 & 1188.55 \\
\hline 14 & 859.804 & 1246.72 & 663.155 & 953.642 & 790.820 & 1080.10 & 985.789 & 1372.88 \\
\hline 15 & 924.129 & 1376.14 & 692.805 & 1058.51 & 840.586 & 1228.59 & 1069.67 & 1545.53 \\
\hline
\end{tabular}

Table 2. For power vs wind speed at Reynold number $=1,200,000$

\begin{tabular}{|c|c|c|c|c|c|c|c|c|}
\hline \multirow{3}{*}{$\begin{array}{l}\text { Wind } \\
\text { speed } \\
\mathrm{m} / \mathrm{s}\end{array}$} & \multicolumn{8}{|c|}{ Power (Hassanli, et al.) } \\
\hline & \multicolumn{2}{|c|}{ 00xx 55xx Multi blade } & \multicolumn{2}{|c|}{ 00xx Multi blade } & \multicolumn{2}{|c|}{ 55xx 00xx Multi blade } & \multicolumn{2}{|c|}{ 55XX Multi blade } \\
\hline & rpm-20 & $\mathrm{rpm}-25$ & $\mathrm{rpm}=20$ & $\mathrm{rpm}-25$ & rpm-20 & $\mathrm{rpm}-25$ & rpm-20 & $\mathrm{rpm}-25$ \\
\hline 1 & -25.3948 & -49.7708 & -21.4752 & -42.664 & -21.5026 & -42.8791 & -25.3614 & -49.8780 \\
\hline 2 & -24.7222 & -48.0237 & -24.0279 & -40.3077 & -20.5764 & -39.0077 & -21.8895 & -46.7087 \\
\hline 3 & -9.56349 & -40.1650 & -14.4824 & -41.0640 & -11.3115 & -34.3708 & -7.21338 & -34.8772 \\
\hline 4 & 21.1599 & -6.44814 & 4.30017 & -22.7345 & 7.27984 & -16.7596 & 23.2237 & -2.00342 \\
\hline 5 & 65.1603 & 41.3278 & 35.9195 & 8.39878 & 39.4725 & 14.2184 & 67.5841 & 45.3588 \\
\hline 6 & 133.764 & 106.973 & 83.2012 & 55.5994 & 88.0399 & 62.2151 & 137.673 & 111.437 \\
\hline 7 & 215.848 & 200.123 & 148.356 & 121.708 & 154.121 & 130.307 & 220.979 & 206.512 \\
\hline 8 & 315.243 & 322.608 & 230.606 & 209.015 & 238.854 & 218.779 & 323.039 & 330.635 \\
\hline 9 & 418.211 & 458.211 & 314.784 & 319.700 & 335.384 & 331.548 & 438.364 & 468.918 \\
\hline 10 & 525.254 & 615.710 & 400.570 & 450.402 & 435.267 & 466.512 & 559.654 & 630.935 \\
\hline 11 & 627.850 & 786.099 & 481.705 & 592.149 & 533.566 & 616.277 & 679.606 & 809.547 \\
\hline 12 & 704.582 & 950.169 & 541.959 & 723.354 & 629.040 & 772.369 & 791.312 & 998.076 \\
\hline 13 & 778.800 & 1114.23 & 602.996 & 853.698 & 717.942 & 928.419 & 892.186 & 1188.55 \\
\hline 14 & 859.804 & 1246.72 & 663.155 & 953.642 & 790.820 & 1080.10 & 985.789 & 1372.88 \\
\hline 15 & 924.129 & 1376.14 & 692.805 & 1058.51 & 840.586 & 1228.59 & 1069.67 & 1545.53 \\
\hline
\end{tabular}


that is $55 \mathrm{xx}$ blade having max twist angle 15 degree at root was considered and its twist angle was changed by 24 degree and 10 degree. The other parameters such as length and chord width were kept constant and then its effect on power output efficiency was evaluated.

It was observed that no major difference occurred on power output efficiency due to change in twist angle up to wind speed of almost $18 \mathrm{~m} / \mathrm{s}$ for this rotor blade. At wind speed greater than $20 \mathrm{~m} / \mathrm{sec}$, an increase in power efficiency was observed.

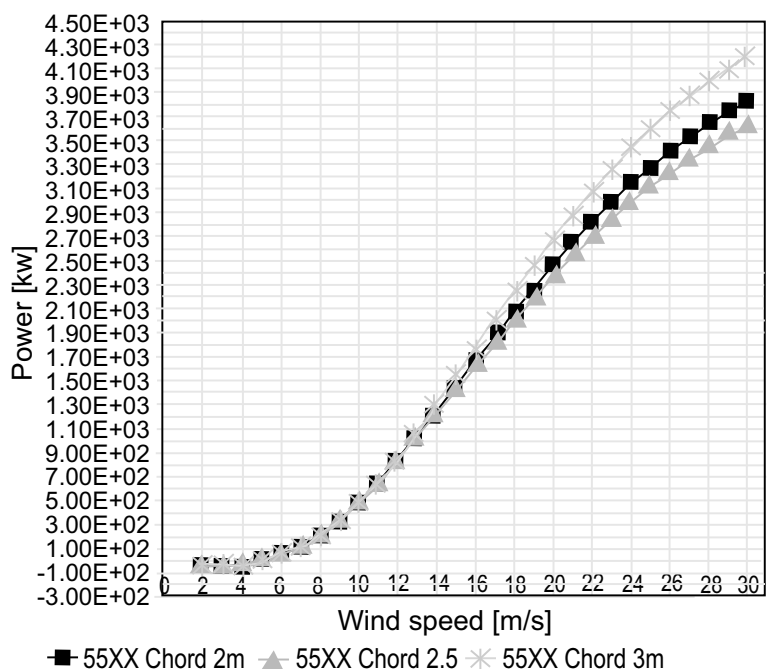

Fig. 10. Graph power verses wind speed at different chord length.

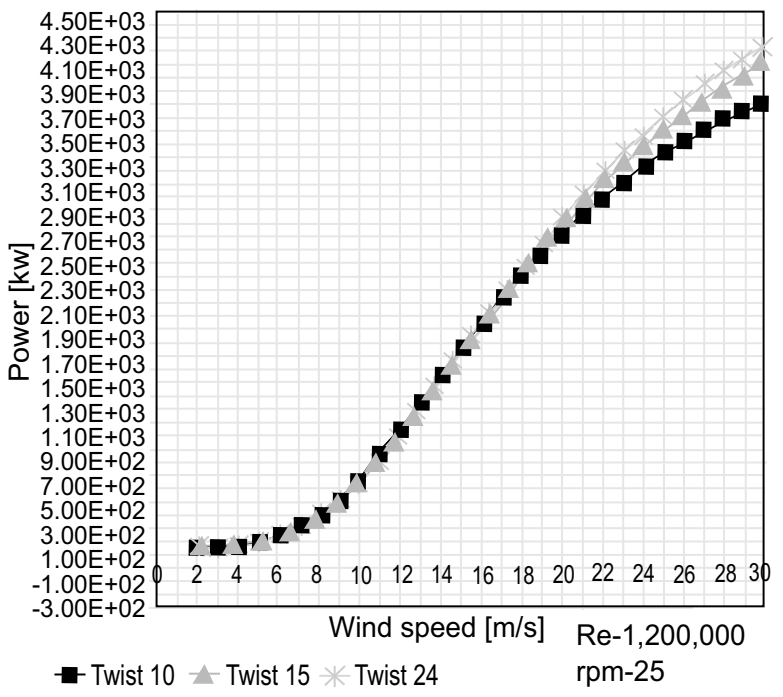

Fig. 11. Power output vs wind speed at different twist angle.
So, the blade design $55 \mathrm{xx}$ is more favourable and no need of change of twist angle required. The large twist angle blade (i.e. 24 degree) has slightly more power output efficiency than the optimum blade design (i.e. 15 degree) but, due to large twist, the main drawback is of manufacturing difficulty and cost (Rahimi, 2018). On the other hand decreasing the twist angle can cause increase in thrust force. So, the $55 \mathrm{xx}$ rotor blade should be considered as an optimal blade design.

Aerodynamic loads. Aerodynamics loads are usually generated by lift and drag forces of the blades aerofoil section which is greatly dependent on wind velocity, surface finish, angle of attack, aerofoils profile and blade velocity. These aerodynamic lift and drag forces are resolved in useful thrust $(\mathrm{T})$ and torque.

After comparison between four different rotor blade designs, the optimal rotor blade design is selected on the basis of maximum power efficiency that is 55XX blade design. The normal forces, tangential forces (i.e. thrust) and torque was calculated by using blade element theory (BEM) formulation as described in Table 3.

Table 3. Aerodynamics forces for $55 x x$ blade

\begin{tabular}{llll}
\hline \hline $\begin{array}{l}\text { Position } \\
(\mathrm{r} / \mathrm{R})\end{array}$ & $\begin{array}{l}\text { Normal force } \\
(\mathrm{N})\end{array}$ & $\begin{array}{l}\text { Tangential force } \\
(\mathrm{N})\end{array}$ & $\begin{array}{l}\text { Torque } \\
(\mathrm{Nm})\end{array}$ \\
\hline 0.06 & 715 & 3433 & 1072.5 \\
0.12 & 1498 & 7152 & 4500 \\
0.2 & 2217 & 12854 & 11085 \\
0.28 & 2190 & 15556 & 15330 \\
0.36 & 2342 & 19591 & 21078 \\
0.44 & 2370 & 23280 & 26070 \\
0.56 & 3423 & 39640 & 47922 \\
0.68 & 3172 & 45077 & 53924 \\
0.8 & 2670 & 37741 & 53400 \\
0.92 & 682 & 118921 & 15699 \\
1 & -1488 & 417046 & -37200 \\
\hline Total & 19791 & 739071 & 212880 \\
\hline \hline
\end{tabular}

\section{Conclusion}

This project spanned the entire process involved with designing and analysing an optimal 25 meter horizontal wind turbine rotor blade for a specific wind corridor. The rotor blade design process starts with the basic collection of aerofoils performance for the wind conditions at the turbine site to determine what can be done to increase the amount of wind energy captured 
by turbine. For this purpose, a 25 meter rotor blade is considered for this study.

After finding the results of different simulations done by Q-Blade software, it is concluded that an optimal design of rotor blade for this site is $55 \mathrm{xx}$ blade. This design blade captures the power from wind at $4 \mathrm{~m} / \mathrm{sec}$ while, the minimum power range for this site is $5 \mathrm{~m} / \mathrm{sec}$. This blade design gives approximately $500 \mathrm{kw}$ at mean wind speed of $9 \mathrm{~m} / \mathrm{s}$ that is a more desirable characteristics. Furthermore, the effect of change in chord length and twist angle on power output efficiency is also analysed in this study. These results show that there is very little effect of these changing on the power output in the wind speed range up to $18 \mathrm{~m} / \mathrm{sec}$.

\section{Acknowledgment}

Authors acknowledge the Department of Mechanical Engineering, International Islamic University, Islamabad, H-10 Campus.

Conflict of Interest. The authors declare no conflict of interest.

\section{References}

Alom, N., Saha, U.K. 2019. Evolution and progress in the development of savonius wind turbine rotor blade profiles and shapes. Journal of Solar Energy Engineering, 141: 150-165.

Bossanyi, E., Savini, B., Iribas, M., Hau, M., Fischer, B., Schlipf, D., Carcangiu, C. 2012. Advanced controller research for multi-MW wind turbines in the UPWIND project. Wind Energy, 15: 119-145.

Broberg, D., Shah, D., Drapcho, S., Brockway, A. 2018. Getting more out of the wind, extending Betz's law to multiple turbines. arXiv preprint arXiv, 18051820.

Ceyhan, O. 2012. Towards 20MW wind turbine, In: Proceedings of High Reynolds Number Effects on Rotor Design. Paper presented at the $50^{\text {th }}$ AIAA ASM Conference, Nashville, Tennessee, USA.

Chaudhary, M.K., Prakash, S. 2019. Investigation of blade geometry and airfoil for small wind turbine blade. Advanced Science, Engineering and Medicine, 11: 448-452.

Das, A., Talapatra, P.K. 2016. Modelling and analysis of a mini vertical axis wind turbine. International Journal of Emerging Technology and Advanced Engineering, 6: 184-188.

Drumheller, D.P., D’Antonio, G.C., Chapman, B.A.,
Allison, C.P., Pierrakos, O. 2015. Design of a micro-wind turbine for implementation in low wind speed environments, paper presented at the 2015 Systems and Information Engineering Design Symposium.

Gorban, A.N., Gorlov, A.M., Silantyev, V.M. 2001. Limits of the turbine efficiency for free fluid flow. Journal of Energy Resources Technology, 123: 311317.

Hassanli, S., Kwok, K.C., Zhao, M. 2018. Performance assessment of a special double skin façade system for wind energy harvesting and a case study. Journal of Wind Engineering and Industrial Aerodynamics, 175: 292-304.

Hau, E. 2006. Wind Turbines: Fundamentals, Technologies, Application, Economics, pp. 408-411, Springer.

Imran, M., Badshah, S., Khan, R. 2019a. Vibration analysis of cracked composite laminated plate: a review. Mehran University Research Journal of Engineering and Technology, 38: 705-716.

Imran, M., Khan, R., Badshah, S. 2019b. Finite element analysis to investigate the influence of delamination size, stacking sequence and boundary conditions on the vibration behaviour of composite plate. Iranian Journal of Materials Science and Engineering, 16: 11-21.

Imran, M., Khan, R., Badshah, S. 2019c. Investigating the effect of delamination size, stacking sequences and boundary conditions on the vibration properties of carbon fiber reinforced polymer composite. Materials Research, 22: http://orcid.org/0002-27046813.

Imran, M., Khan, R., Badshah, S. 2018. Vibrtaion analysis of cracked composite laminated plate. Pakistan Journal of Scientific and Industrial Research Series A: Physical Sciences, 61: 84-90.

Kaveh, A., Sabeti, S. 2019. Optimal design of monopile offshore wind turbine structures using CBO, ECBO, and VPS algorithms. Scientia Iranica, 26: 12321248.

Lanzafame, R., Messina, M. 2010. Power curve control in micro wind turbine design. Energy, 35: 556-561.

Maalawi, K., Badr, M. 2003. A practical approach for selecting optimum wind rotors. Renewable Energy, 28: 803-822.

Manwell, J.F., McGowan, J.G., Rogers, A.L. 2010. Wind Energy Explained, Theory, Design and Application, $2^{\text {nd }}$ edition, J. F. Manwell, J. G. McGowan, A. L. Rogers (eds.), John Wiley \& Sons, Ltd. 
Rahimi, M. 2018. Control and performance assessment of variable rotor resistance based wind turbines regarding the aerodynamic power fluctuations. Scientia Iranica, 25: 1593-1607.

Raut, M.S., Shrivas, M.S., Sanas, M.R., Sinnarkar, M.N., Chaudhary, M. 2017. Simulation of micro wind turbine blade in Q-Blade. International Journal for Research in Applied Science and Engineering Technology, 5: 256-262.

Saeed, A. 2018. Potential of wind power in Pakistan. Journal of Information Communication Technologies and Robotic Applications, 28-35.

Schubel, P.J., Crossley, R.J. 2012. Wind turbine blade design. Energies, 5: 3425-3449.

Song, D., Yang, J., Fan, X., Liu, Y., Liu, A., Chen, G., Joo, Y.H. 2018. Maximum power extraction for wind turbines through a novel yaw control solution using predicted wind directions. Energy Conversion and Management, 157: 587-599.

Tang, H., Lam, K.M., Shum, K.M., Li, Y. 2019. Wake effect of a horizontal axis wind turbine on the performance of a downstream turbine. Energies, 12: $2395-2405$.

Tong, W. 2010. Wind Power Generation and Wind Turbine Design, Wit Press, Kollmorgan Corporation, USA. (www.WitPress.com).

Wang, L., Tang, X., Liu, X. 2012. Optimized chord and twist angle distributions of wind turbine blade considering Reynolds number effects. Wind Energy, Materials, Engineering and Policies (WEMEP). http://www.citeseerx.ist.P.S.O.edu.

Yurdusev, M., Ata, R., Cetin, N. 2006. Assessment of optimum tip speed ratio in wind turbines using artificial neural networks. Energy, 31: 2153-2161. 